\title{
Validation of the PHQ-9 depression scale in Ethiopian cancer patients attending the oncology clinic at Tikur Anbessa specialized hospital
}

Mikyas Degefa ${ }^{1 *}$, Benyam Dubale ${ }^{2}$, Fikirte Bayouh², Biniyam Ayele $^{3}$ and Yared Zewde $^{3}$

\begin{abstract}
Background: Although depression is highly prevalent among cancer patients, it is often underdiagnosed and poorly managed particularly in developing nations. These shortcomings can have substantial adverse effects not only on the disease prognosis but also on patients' quality of life. The Patient Health Questionnaire-9 is a widely used depression screening tool but it has not been validated among patients with chronic illnesses such as cancer in Ethiopia. We aim to validate the PHQ-9 among Ethiopian cancer patients in an outpatient setting.

Methods: A cross-sectional study was conducted among cancer patients attending the oncology clinic at Tikur Anbessa Specialized Hospital (TASH). We assessed criterion validity and performance of the PHQ-9 test against the gold standard Mini-International Neuropsychiatric Interview (MINI) diagnostic tool among patients with cancer. The MINI was administered by psychiatric nurses who were blind to the initial PHQ-9 screening tool.

Results: A total of 163 patients completed the 2 stages of a diagnostic interview in the study. The majority (64\%) of the participants were women, the mean age was 46 (13.5) years. Using the gold standard MINI test the prevalence of Major Depressive Episode (MDE) was 15\%. The internal consistency (Cronbach's a) for PHQ-9 was 0.78 suggesting good (acceptable) internal consistency for the reliability of the test scores. When the total PHQ-9 score was used to identify cases of MDE, the Area under the Curve (AUC) was 0.93 (95\% confidence interval [Cl], 0.88-0.97) on Receiver Operating Characteristic (ROC) analysis. This shows evidence for the excellent discriminating power of the PHQ-9 between cases and non-cases of MDE. At cutoff point $\geq 4$, the PHQ-9 had a sensitivity of $88 \%$ and specificity of $78.1 \%$ on the ROC curve to detect MDE.

Conclusion: PHQ-9 is a reliable and valid instrument to detect MDE among individuals with chronic conditions such as cancer patients in outpatient settings and it can be used in resource-limited settings for early diagnosis and proper therapy of such patients.
\end{abstract}

Keywords: Validation, Depression, Patient Health Questionnaire-9 (PHQ-9), Cancer, Ethiopia

\footnotetext{
* Correspondence: mikyas101@gmail.com

${ }^{1}$ Amanuel Mental Specialized Hospital, Addis Ababa, Ethiopia

Full list of author information is available at the end of the article
}

(C) The Author(s). 2020 Open Access This article is licensed under a Creative Commons Attribution 4.0 International License, which permits use, sharing, adaptation, distribution and reproduction in any medium or format, as long as you give appropriate credit to the original author(s) and the source, provide a link to the Creative Commons licence, and indicate if changes were made. The images or other third party material in this article are included in the article's Creative Commons licence, unless indicated otherwise in a credit line to the material. If material is not included in the article's Creative Commons licence and your intended use is not permitted by statutory regulation or exceeds the permitted use, you will need to obtain permission directly from the copyright holder. To view a copy of this licence, visit http://creativecommons.org/licenses/by/4.0/ The Creative Commons Public Domain Dedication waiver (http://creativecommons.org/publicdomain/zero/1.0/) applies to the data made available in this article, unless otherwise stated in a credit line to the data. 


\section{Background}

Cancer is a chronic medical illness with 18.1 million new cases and 9.6 million deaths only in 2018. Cancer is also an emerging public health issue in Africa, with estimates of 811,200 new cases and 533,800 cancer deaths in the same year. In Ethiopia, the annual incidence and mortality from all cancer types were 67,500 and 50,000 cases respectively [1]. Depression is one of the most common psychiatric comorbidities following the diagnosis of cancer. The prevalence of depression among patients with cancer ranged widely from 3\% up to $50 \%$ depending on the method of ascertaining depression, study population concerning to cancer type, stage, treatment modality, and the use of different instruments. However most estimates for the prevalence of depression falling between 10 and 25\% [2]. Studies show that clinicians working in cancer services have recognized that depression is often undiagnosed and untreated, and these shortcomings can have substantial effects, not only on patients' quality of life but also on their acceptance of cancer treatment [3, 4] This co-morbidity of chronic medical condition with depression is a public health concern due to its negative effects on the course of the illness and its impact on overall prognosis $[5,6]$.

Detecting depression is often difficult in cancer patients because of overlapping symptoms such as fatigue, loss of appetite, sleep disturbance, and also the effects of cancer treatment have been thought to have a confounding effect on the assessment of depression [7, 8]. In addition to this, stigma, lack of healthcare providers trained in mental health, and paucity of validated screening and diagnostic tools also contribute to the low level of diagnosis and treatment of depression, particularly in Low and Middle- Income Countries (LMIC) [9-11]. Screening instruments such as the PHQ-9 have been designed to detect MDE according to the Diagnostic and Statistical Manual of Mental Disorders-IV text revision (DSM-IV-TR). This instrument is free, takes a brief time to administer, and simple to score. This makes it ideal for use in clinical settings where administering comprehensive structured or semi-structured screening instruments can be difficult due to busy clinics and few health professionals [12]. In two different studies done in Kenya among patients with chronic medical conditions, PHQ-9 was shown to be a reliable instrument for the detection of depression $[13,14]$.

In Ethiopia, two prior studies concluded that PHQ-9 was a valid and reliable instrument for detection of major depressive disorders among patients in outpatient settings and rural communities, while the latter study also emphasized the need for further study in the utility of the screening tool in clinical settings $[15,16]$. Structured diagnostic interview tools are available for diagnosis of depression in patients with chronic medical conditions including the
MINI which allows diagnosis of depression according to DSM-IV and ICD-10 criteria [17].

The objective of this study is to evaluate the criterion validity of the PHQ-9 for detecting depression among patients with cancer attending the outpatient oncology clinic at Tikur Anbessa Specialized Hospital.

\section{Methods}

\section{Study setting and period}

Tikur Anbessa Specialized Hospital (TASH) is the largest and oldest referral hospital in Ethiopia which provides comprehensive multidisciplinary medical service for the nation including oncology service. The oncology care in TASH is comprised of inpatient and outpatient services including the only radiotherapy service in the country. It provides services for patients referred from different parts of Ethiopia. The data were collected between August and September 2016.

\section{Study population}

The study population was all adult patients with a diagnosis of cancer attending the outpatient oncology services in TASH.

\section{Sample size}

Using a convenient sampling technique, we enrolled all consecutive patients who came for follow up during the study period. The sample size was determined using a formula for calculating sensitivity and specificity for single tests [18]. With sensitivity at $85 \%$ and a prevalence of $30 \%$, the total number of patients expected in our study was 163 . This allowed the estimated sensitivity to be within the confidence limits of 80 and $90 \%$. Patients who were younger than 18 years of age, those who were in severe distress requiring emergency care, and those who failed to communicate in Amharic (the federal working language of Ethiopia) were excluded.

\section{Study design}

We used a hospital-based cross-sectional study design. Participants' socio-demographic characteristics including age, educational level, marital status, occupation, and residential place were documented. Types of cancer, time of diagnosis, stage of cancer, treatment history, and duration of the illness were retrieved from the chart and the participants. The study questioners including the PHQ-9 tool were administered by two oncology nurses. The MINI was administered by two psychiatric nurses. All data collectors received in-depth training on the study instruments, ethical conduct of research, and data collection techniques for 3 days by a qualified independent mental health researcher. 


\section{Screening test}

The PHQ-9 comprises nine items that can be scored from 0 (not at all) to 3 (nearly every day) and the total score ranges from 0 to 27 to measure depression severity $[19,20]$. So far only one study has been conducted in Ethiopia using the Amharic translated version of PHQ-9 in a medical outpatient setting for detection of depression [21].

\section{Diagnostic criterion measure of depression}

The MINI is a gold standard brief assessment tool that allows the diagnosis of depression according to DSM-IV and ICD-10 criteria [22]. It is modularized and each major diagnostic condition is represented by a module. For this validation study, the module on Major Depressive Episode was used.

\section{Data collection and management Two-stage sample selection}

After getting a written informed consent, sociodemographic and clinical data together with the test assessment (PHQ-9) score for each participant were collected by two trained oncology nurses. Later on the same day, each patient was again re-assessed using the gold standard assessment MINI by two qualified psychiatric nurses. The data collectors readout and elaborated all the questions for the illiterate participants. The psychiatric nurses who were conducting the criterion assessment interviews were blinded to the results of the PHQ-9 and vice versa.

\section{Data analysis}

Data were analyzed using the Statistical Package for Social Sciences version 20.0 software package (SPSS Inc., Chicago, IL, USA). Initially, one case was excluded due to a missing value in the PHQ-9 data and then a sample of 162 cases were categorized into cases of MDE and non-cases based on the MINI assessment to determine the validity of the instrument.

The sensitivity, specificity, positive likelihood ratio, and negative likelihood ratio were calculated to determine different cutoff scores for PHQ-9. Receiver Operating Characteristic (ROC) curve was used to identify optimal balance between sensitivity and specificity for the determination of the best PHQ-9 cutoff score for the diagnosis of major depression. Youden index (sensitivity+ specificity-1) was converted into a percentage and was used as an additional metric for cutoff determination, where measure above $50 \%$ was considered as acceptable values of diagnostic accuracy [23].

The area under the curve (AUC) was used to address the performance of the test. Reliability related to internal consistency was measured by Cronbach's alpha coefficient (Cronbach's $\alpha$ ).

\section{Results}

Socio-demographic characteristics

A total of 163 patients completed the two-stage process of the diagnostic interview. The mean age of the participants was $46( \pm 13.5)$ years and $64 \%$ of them were females. More than two-thirds $(73 \%)$ of our participants were educated from which $37 \%$ earned a college degree. Two-thirds $(66.3 \%)$ of the participants were married. One in three (31.3\%) described themselves as housewives and $70 \%$ were from rural areas (Table 1).

Table 1 Description of the socio-demographic characteristics of participants

\begin{tabular}{|c|c|c|}
\hline & Frequency & Percent (\%) \\
\hline \multicolumn{3}{|l|}{ Age in years } \\
\hline $18-40$ & 68 & 42 \\
\hline $41-60$ & 73 & 45 \\
\hline$>60$ & 22 & 13 \\
\hline \multicolumn{3}{|l|}{ Gender } \\
\hline Male & 59 & 36 \\
\hline Female & 104 & 64 \\
\hline \multicolumn{3}{|l|}{ Literacy } \\
\hline Literate & 118 & 73 \\
\hline Illiterate & 43 & 27 \\
\hline \multicolumn{3}{|l|}{ Level of Education } \\
\hline Elementary education & 34 & 29 \\
\hline High school education & 29 & 25 \\
\hline College \& above & 44 & 37 \\
\hline Informal education & 7 & 6 \\
\hline No education & 4 & 3 \\
\hline \multicolumn{3}{|l|}{ Marital status } \\
\hline Married & 108 & 66.3 \\
\hline Single & 19 & 11.7 \\
\hline Divorced & 9 & 5.5 \\
\hline Widowed & 18 & 11.0 \\
\hline \multicolumn{3}{|l|}{ Residence place } \\
\hline Urban & 48 & 29.4 \\
\hline Rural & 115 & 70.6 \\
\hline \multicolumn{3}{|l|}{ Occupation } \\
\hline Housewives & 51 & 31.3 \\
\hline Farmer & 26 & 16 \\
\hline Merchant & 25 & 15.3 \\
\hline Government & 28 & 28.2 \\
\hline Student & 6 & 3.7 \\
\hline Daily laborer & 2 & 1.2 \\
\hline Unemployed & 3 & 1.8 \\
\hline Other & 4 & 2.5 \\
\hline
\end{tabular}


Distribution of cancer-related clinical characteristics

The most frequent type of cancer identified was breast cancer $28.7 \%$ followed by skin cancer (16\%) and gastrointestinal cancer (12\%). According to TNM classification more than half (53\%) of the patients were at stage II and followed by stage III at $27 \%$ and stage I at $18 \%$. At the time of screening, almost half (47\%) were receiving chemotherapy only, while $29 \%$ were receiving both treatments. The majority of the participants (81\%) got their diagnosis between 1 and 5 years while those diagnosed in the past 1 year were $5.5 \%(n=9)$ (Table 2$)$.

\section{Depression among cancer patients}

The prevalence of MDE among cancer patients in this study using the gold standard MINI was $15.3 \%(n=25)$. A quarter of cervical cancer patients were diagnosed with MDE which is the highest compared to other types of cancer. Nineteen percent $(n=15)$ of patients with stage II cancer and $24 \%(n=8)$ of patients receiving only radiotherapy treatment were diagnosed with MDE (Table 3). The mean score of PHQ-9 was 2.81 and on

Table 2 Frequency distribution of cancer-related clinical characteristics of study participants

\begin{tabular}{|c|c|c|}
\hline $\begin{array}{l}\text { Cancer-related variables } \\
\text { Types of cancer }\end{array}$ & $\begin{array}{l}\text { Frequency } \\
\text { (N) }\end{array}$ & $\begin{array}{l}\text { Percent } \\
(\%)\end{array}$ \\
\hline Breast & 46 & $28.7 \%$ \\
\hline Skin & 26 & $16 \%$ \\
\hline Gastrointestinal & 22 & $13.5 \%$ \\
\hline Cervical & 20 & $12.2 \%$ \\
\hline Oropharyngeal & 15 & $9.1 \%$ \\
\hline Prostate & 9 & $5.5 \%$ \\
\hline Others & 25 & $15 \%$ \\
\hline \multicolumn{3}{|l|}{ Stages of cancer } \\
\hline Stage I & 26 & $17.8 \%$ \\
\hline Stage ॥ & 70 & $53.4 \%$ \\
\hline Stage III & 40 & $27.4 \%$ \\
\hline Stage IV & 2 & $1.4 \%$ \\
\hline \multicolumn{3}{|l|}{ Treatment } \\
\hline Chemotherapy only & 77 & $47.2 \%$ \\
\hline Radiotherapy only & 33 & $20.2 \%$ \\
\hline Chemotherapy \& radiotherapy only & 48 & $29.4 \%$ \\
\hline Chemotherapy \& surgery only & 2 & $1.2 \%$ \\
\hline Radiotherapy \& surgery only & 1 & $0.6 \%$ \\
\hline Not on treatment & 2 & $1.2 \%$ \\
\hline \multicolumn{3}{|l|}{ Duration of IIIness } \\
\hline$<1$ year & 9 & $5.5 \%$ \\
\hline Between 1 year and 5 years & 132 & $81 \%$ \\
\hline$>5$ years & 22 & $13.5 \%$ \\
\hline
\end{tabular}

Table 3 Prevalence of depression using MINI among different cancer types, stage, and different treatment

\begin{tabular}{llll}
\hline Types of cancer & Total (N) & MDE (N) & $\begin{array}{l}\text { Percent (\%) } \\
\text { MDE }\end{array}$ \\
\hline Breast & 47 & 6 & $13 \%$ \\
Skin & 26 & 4 & $15 \%$ \\
Gastrointestinal & 22 & 2 & $9 \%$ \\
Cervical & 20 & 5 & $25 \%$ \\
Oropharyngeal & 15 & 2 & $13 \%$ \\
Prostate & 9 & 1 & $11 \%$ \\
Others & 24 & 5 & $21 \%$ \\
Total & 163 & 25 & $15.3 \%$ \\
Cancer stage & & & \\
$\quad$ Stage I & 26 & 3 & $11.5 \%$ \\
$\quad$ Stage II & 78 & 15 & $19 \%$ \\
$\quad$ Stage III & 40 & 3 & $7.5 \%$ \\
$\quad$ Stage IV & 2 & 1 & $50 \%$ \\
Total & 146 & 22 & $15.3 \%$ \\
Treatment & & & \\
Chemotherapy only & 77 & 7 & $9 \%$ \\
Radiotherapy only & 33 & 8 & $24 \%$ \\
Chemo \& radiotherapy only & 48 & 7 & $14.6 \%$ \\
Chemotherapy \& surgery only & 2 & 0 & $0 \%$ \\
$\quad$ Radiotherapy \& surgery & 1 & 1 & $100 \%$ \\
$\quad$ No treatment & 2 & 2 & $100 \%$ \\
Total & 163 & 25 & $15.3 \%$ \\
\hline
\end{tabular}

each item, the mean score ranged from 0.06 (suicidal ideation) to 0.56 (loss of energy) (Table 4).

\section{Reliability}

The reliability coefficient, Cronbach's $\alpha$ was 0.78 indicating acceptable internal consistency for the reliability of the PHQ-9 test scores.

Table 4 Mean scores of PHQ-9 Items

\begin{tabular}{lll}
\hline PHQ Items & Mean & Standard Deviation \\
\hline Loss of interest & .38 & .68 \\
Feeling depressed & .42 & .70 \\
Sleep problems & .42 & .71 \\
Loss of energy & .56 & .75 \\
Appetite problems & .37 & .69 \\
Self-blame & .19 & .50 \\
Concentration problems & .28 & .61 \\
Agitation/retardation & .13 & .37 \\
Suicidal ideations & .06 & .33 \\
Sum score & 2.81 & 5.37 \\
\hline
\end{tabular}




\section{Criterion validity of the screening instruments against a gold standard}

After excluding one missing case, a total of 162 cases were analyzed to determine the criterion validity of PHQ-9 against the gold standard MINI. The area under the ROC curve was 0.93 (95\% confidence interval [CI], 0.88-0.97) on analysis. According to this result, PHQ-9 showed an excellent discriminating power to differentiate between cases and non-cases of MDE. The detailed description of the ROC curve for PHQ-9 against the gold standard (MINI) is shown in Fig. 1. The optimal cutoff point with maximum sensitivity and without loss of significant specificity was $\geq 4$; the PHQ- 9 had a sensitivity of $88 \%$ and specificity of $78.1 \%$ on the ROC curve. At this cutoff score, a person testing positive for MDE is 4 times more likely than a person who doesn't have MDE to be tested positive. Youden index also showed a higher value with $66.1 \%$. The detailed description of the cutoff scores of PHQ-9 against the gold standard (MINI) is shown in Table 5.

\section{Discussion}

In patients with chronic conditions recognizing and managing depression is important due to its potential in improving medication adherence, reducing the progression of the disease, and improving quality of life [24]. In our study, the prevalence of depression in adult patients with cancer attending outpatient clinics using the gold standard was $15 \%$. This is comparable with pooled mean prevalence ranging from 8 to $24 \%$ in a meta-analysis of

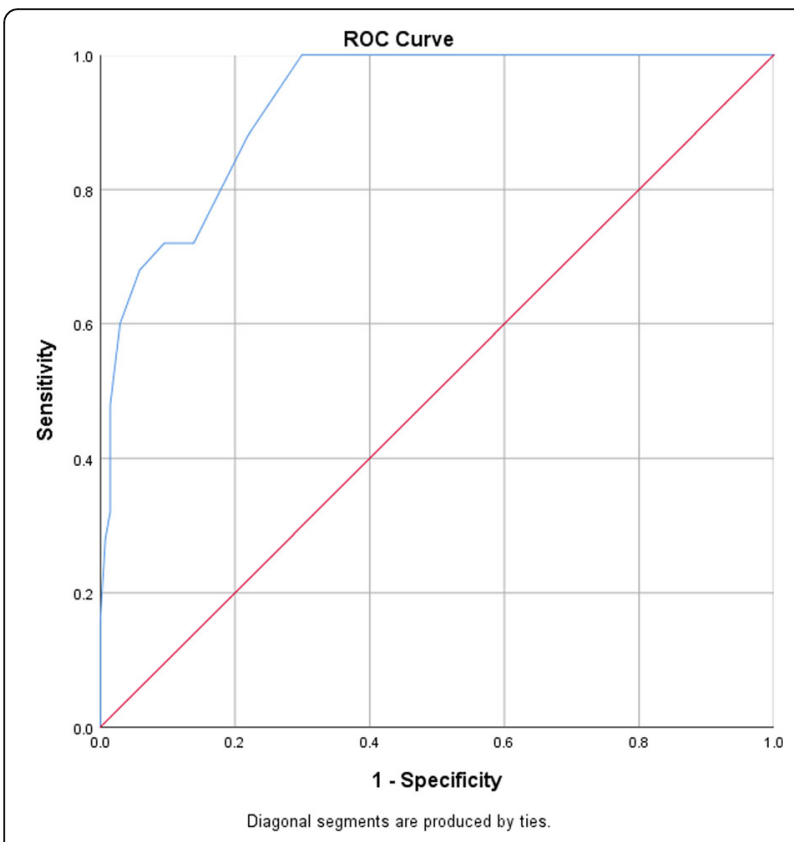

Fig. 1 ROC curves for PHQ-9 against gold standard (MINI) diagnosis of MDE
Table 5 PHQ-9 cutoff scores against the gold standard of study participants

\begin{tabular}{lllllll}
\hline $\begin{array}{l}\text { Optimal } \\
\text { cutoff point }\end{array}$ & Sensitivity & Specificity & +LR & -LR & $\begin{array}{l}\text { Correctly } \\
\text { classified }\end{array}$ & $\begin{array}{l}\text { Youden } \\
\text { index }\end{array}$ \\
\hline$\geq 1$ & $100 \%$ & $47.4 \%$ & 1.9 & 0 & $55.5 \%$ & $47.4 \%$ \\
$\geq 2$ & $100 \%$ & $58.4 \%$ & 2.4 & 0 & $64.8 \%$ & $58.4 \%$ \\
$\geq 3$ & $100 \%$ & $70 \%$ & 3.4 & 0 & $74.7 \%$ & $70 \%$ \\
$\geq 4$ & $88 \%$ & $78.1 \%$ & 4 & 0.09 & $79.6 \%$ & $66.1 \%$ \\
$\geq 5$ & $72 \%$ & $86.1 \%$ & 5.2 & 0.24 & $83.9 \%$ & $58.1 \%$ \\
$\geq 6$ & $72 \%$ & $90.5 \%$ & 7.5 & 0.25 & $87.6 \%$ & $62.5 \%$ \\
$\geq 7$ & $68 \%$ & $94.1 \%$ & 11.7 & 0.3 & $90.1 \%$ & $62.1 \%$ \\
$\geq 8$ & $60 \%$ & $97.1 \%$ & 20.6 & 0.3 & $91.3 \%$ & $57.1 \%$ \\
$\geq 9$ & $48 \%$ & $98.5 \%$ & 33.1 & 0.51 & $90.7 \%$ & $46.5 \%$ \\
$\geq 10$ & $32 \%$ & $98.5 \%$ & 22 & 0.67 & $88.2 \%$ & $30.5 \%$ \\
$\geq 11$ & $28 \%$ & $99.2 \%$ & 38.3 & 0.71 & $88.2 \%$ & $27.2 \%$ \\
$\geq 12$ & $16 \%$ & $100 \%$ & 0 & 0.84 & $87 \%$ & $16 \%$ \\
$\geq 13$ & $12 \%$ & $100 \%$ & 0 & 0.87 & $86.4 \%$ & $12 \%$ \\
$\geq 14$ & $4 \%$ & $100 \%$ & 0 & 0.96 & $85.1 \%$ & $4 \%$ \\
\hline
\end{tabular}

211 studies [25]. Another meta-analysis on 94 studies among cancer patients reported a pooled prevalence of depression at $16.3 \%$ [26]. This result demonstrates a high prevalence of depression among patients with a diagnosis of cancer and underscores the need for a brief reliable and valid instrument for better detection and improved quality care. In this study, PHQ-9 has acceptable internal consistency with Cronbach's $\alpha$ 0.78. A similar finding (Cronbach's $\alpha$ of 0.84 ) was reported in Germany [27]. When we turn to the case detection property of the instrument it's found to be highly accurate with the area under the curve (AUC) of 0.93 (95\% [CI], 0.88-0.97) on ROC analysis. This is evidence of an excellent discriminating power between cases and noncases of MDE. Our result was comparable to a similar study on cancer patients attending an outpatient clinic with a ROC curve of 0.94 (95\% confidence interval [CI], 0.93-0.95) [28].

The choice of the optimal cutoff score is always a tradeoff between sensitivity and specificity. A lower cutoff score makes the questionnaire very sensitive and inclusive, whereas a higher cutoff score will make it more specific at the cost of missing some cases [20]. Metaanalysis 18 studies and 7180 participants found the PHQ-9 with cutoff scores between 8 and 11 have acceptable screening properties for detecting depression [29]. In our study at a lower cutoff point of $\geq 4$, the PHQ-9 had a sensitivity of $88 \%$ and specificity of $78.1 \%$. With a similar cut off point, our study yielded a better sensitivity and specificity compared to study done at South Africa in chronic care patients with sensitivity $87 \%$ and specificity $63.3 \%$ [30]. A study on somatic symptoms in depression concluded that somatic symptoms were 
common but had less impact on the diagnosis of depression, rather the core depressive symptoms of depression were better predictors for the diagnosis [31]. In our study, the mean scores of PHQ-9 items showed a relatively similar distribution between core symptoms of depression and somatic symptoms.

The strength of this study is that it is one of a handful of studies to consider the validity of the PHQ-9 in patients with the diagnosis of cancer in sub-Saharan Africa, the first in Ethiopia, and also one the few studies to provide the prevalence of depression among cancer patients in the country. We also used instruments that were previously translated into the Amharic language and validated in different settings. Data collectors and psychiatric nurses were blinded to the results of criterion assessment and screening instruments. Limitations of the study include the relatively small sample size, inability to test psychometric properties, and the factorial structure of the PHQ-9. We did not perform a regression analysis for the assessment of expected mean scores to evaluate the PHQ-9 mean values for different cancer types and we were also unable to explain the low rates of surgery among patients with cancer.

\section{Conclusion}

The Amharic version of PHQ-9 appears to be a reliable and valid instrument to identify Major Depressive Episode among patients with chronic conditions such as cancer. Since it is free, brief, and easy to administer, this instrument can be used in resource-limited countries for depression screening.

\begin{abstract}
Abbreviations
AAU: Addis Ababa University; DSM-IV-IR: Diagnostic and Statistical Manual of Mental Disorders-IV text revision; ICD-10: International Classification of Diseases, 10th revision; MDE: Major Depressive Episode; MINI: MiniInternational Neuropsychiatric Interview; PHQ-9: Patient Health Questionnaire - 9-item version; ROC: Receiver operating characteristic; TASH: Tikur Anbessa Specialized Hospital
\end{abstract}

\section{Acknowledgments}

I would like to extend my heartfelt gratitude to all the nursing staff at both oncology referral clinics were the survey was conducted and the oncology department, above all my heartfelt gratitude, goes to all participants of this study. Last but not least I would like to thank Dr. Charlotte Hanlon for the help in the data analysis and further guidance.

\section{Authors' contributions}

MD was involved in data acquisition, analysis, interpretation, review, and critique. $B D$ and $F B$ were involved in the analysis, interpretation, review, and critique. $B A$ and $Y Z$ are in review and critique. MD, BA, and $Y Z$ participated in manuscript preparation. All authors' read and approved the final manuscript.

\section{Authors' information}

$\mathrm{MD}$ is a senior medical professional, psychiatrist working at Amanuel Mental Specialized Hospital, Federal Ministry of Health. He is actively involved in clinical service and research activities in the field of Psychiatry. BD is an assistant professor of Psychiatry at the Department of Psychiatry, College of Health Sciences Addis Ababa University. He is actively involved in clinical practice and research in psychiatry including a publication of validation study. FB is an assistant professor of Psychiatry at the Department of
Psychiatry, College of Health Sciences Addis Ababa University. She is actively engaged in clinical practice and research activities in psychiatry with prior experience in validation studies. BA is an assistant professor of Neurology at the Department of Neurology, College of Health Sciences Addis Ababa University. He is actively involved in clinical practice and researches in the field of neurosciences. $Y Z$ is an assistant professor of Neurology at the Department of Neurology, College of Health Sciences Addis Ababa University. He is actively engaged in clinical practice and researches in the field of neurosciences.

\section{Funding}

No funding was received from any organization or individuals.

\section{Availability of data and materials}

All data sets on which the conclusions of the manuscript will be available as spreadsheets documents upon request from the corresponding author.

\section{Ethics approval and consent to participate}

The study received ethical approval from the scientific committee of the department of psychiatry; College of Health Science; Addis Ababa University, and all participants were provided with written informed consent.

\section{Consent for publication}

Not applicable.

\section{Competing interests}

The authors declare that they have no competing interests.

\section{Author details}

${ }^{1}$ Amanuel Mental Specialized Hospital, Addis Ababa, Ethiopia. ${ }^{2}$ Department of Pyschiatry, College of Health Science, Addis Ababa University, Addis Ababa, Ethiopia. ${ }^{3}$ Department of Neurology, College of Health Science, Addis Ababa University, Addis Ababa, Ethiopia.

Received: 8 April 2020 Accepted: 2 September 2020

Published online: 10 September 2020

\section{References}

1. World Health Organization, latest global cancer data Globocan Database, 2018, http://gco.iarc.fr/.

2. Massie MJ. Prevalence of depression in patients with cancer. J Natl Cancer Inst Monogr. 2004;32:57-71.

3. Fallowfield L, Ratcliffe D, Jenkins $V$, Saul J. Psychiatric morbidity and its recognition by doctors in patients with cancer. Br J Cancer. 2001;84(8):10115.

4. Hardman A, Maguire $P$, Crowther D. The recognition of psychiatric morbidity on a medical oncology ward. J Psychosom Res. 1989;33(2):235-9.

5. Thombs BD, Ziegelstein RC, Whooley MA. Optimizing detection of major depression among patients with coronary artery disease using the patient health questionnaire: data from the heart and soul study. J Gen Intern Med. 2008;23(12):2014-7.

6. Breuer E, Myer L, Struthers H, Joska J. HV/AIDS and mental health research in sub-Saharan Africa: a systematic review. Afr J AIDS Res. 2011;10(2):101-22.

7. Newport DJ, Nemeroff CB. Assessment and treatment of depression in the cancer patient. J Psychosom Res. 1998;45(3):215-37.

8. Bukberg J, Penman D, Holland JC. Depression in hospitalized cancer patients. Psychosom Med. 1984;46(3):199-212

9. Wig NN. WHO and mental health--a view from developing countries. Bull World Health Organ. 2000;78(4):502-3.

10. Patel V, Araya R, Chowdhary N, et al. Detecting common mental disorders in primary care in India: a comparison of five screening questionnaires. Psychol Med. 2008;38(2):221-8.

11. Patel V, Sartorius N. From science to action: the lancet series on global mental health. Curr Opinion Psychiatry. 2008;21(2):109-13.

12. Spitzer RL, Kroenke K, Williams JB. Validation and utility of a self-report version of PRIME-MD: the PHQ primary care study. Primary care evaluation of mental disorders. Patient health questionnaire. JAMA. 1999;282(18):1737-44.

13. Monahan PO, Shacham E, Reece M, et al. Validity/reliability of PHQ-9 and PHQ-2 depression scales among adults living with HIV/AIDS in western Kenya. J Gen Intern Med. 2009;24(2):189-97. 
14. Omoro SA, Fann JR, Weymuller EA, Macharia IM, Yueh B. Swahili translation and validation of the patient health Questionnaire-9 depression scale in the Kenyan head and neck cancer patient population. Int J Psychiatry Med. 2006:36(3):367-81.

15. Woldetensay YK, Belachew T, Tesfaye M, et al. Validation of the patient health questionnaire (PHQ-9) as a screening tool for depression in pregnant women: Afaan Oromo version. PLoS One. 2018;13(2):e0191782.

16. Hanlon C, Medhin G, Selamu M, et al. Validity of brief screening questionnaires to detect depression in primary care in Ethiopia. J Affect Disord. 2015;186:32-9.

17. Orlandi L, Pinho JF, Murad MGR, et al. Depression diagnosed by the mini international neuropsychiatric interview plus (MINI) in patients with chronic obstructive pulmonary disease: relationship with functional capacity and quality of life. BMC Psychiatry. 2016;9:65.

18. Buderer NM. Statistical methodology: I. incorporating the prevalence of disease into the sample size calculation for sensitivity and specificity. Acad Emerg Med. 1996;3(9):895-900.

19. Kroenke K, Spitzer RL, Williams JB. The PHQ-9: validity of a brief depression severity measure. J Gen Intern Med. 2001;16(9):606-13.

20. Löwe B, Kroenke K, Herzog W, Gräfe K. Measuring depression outcome with a brief self-report instrument: sensitivity to change of the patient health questionnaire (PHQ-9). J Affect Disord. 2004;81(1):61-6.

21. Gelaye B, Williams MA, Lemma S, et al. Validity of the patient health Questionnaire-9 for depression screening and diagnosis in East Africa. Psychiatry Res. 2013;210(2):653-61.

22. Sheehan DV, Lecrubier Y, Sheehan KH, et al. The Mini-International Neuropsychiatric Interview (M.I.N.I.): the development and validation of a structured diagnostic psychiatric interview for DSM-IV and ICD-10. J Clin Psychiatry. 1998;59(Suppl 20):22-57.

23. Youden WJ. Index for rating diagnostic tests. Cancer. 1950;3(1):32-5.

24. National Collaborating Centre for Mental Health (UK). Depression: The Treatment and Management of Depression in Adults (Updated Edition). Leicester: British Psychological Society; 2010

25. Krebber AM, Buffart LM, Kleijn G, et al. Prevalence of depression in cancer patients: a meta-analysis of diagnostic interviews and self-report instruments. Psychooncology. 2014;23(2):121-30.

26. Mitchell AJ, Chan M, Bhatti H, et al. Prevalence of depression, anxiety, and adjustment disorder in oncological, haematological, and palliative-care settings: a meta-analysis of 94 interview-based studies. Lancet Oncol. 2011; 12(2):160-74.

27. Hinz A, Mehnert A, Kocalevent RD, et al. Assessment of depression severity with the PHQ-9 in cancer patients and in the general population. BMC Psychiatry. 2016;16:22.

28. Thekkumpurath P, Walker J, Butcher I, et al. Screening for major depression in cancer outpatients: the diagnostic accuracy of the 9-item patient health questionnaire. Cancer. 2011;117(1):218-27.

29. Manea L, Gilbody S, McMillan D. Optimal cut-off score for diagnosing depression with the patient health questionnaire (PHQ-9): a meta-analysis. CMAJ. 2012;184(3):E191-6.

30. Bhana A, Rathod SD, Selohilwe O, et al. The validity of the patient health questionnaire for screening depression in chronic care patients in primary health care in South Africa. BMC Psychiatry. 2015;15:118.

31. Okulate GT, Olayinka MO, Jones OB. Somatic symptoms in depression: evaluation of their diagnostic weight in an African setting. Br J Psychiatry. 2004:184:422-7.

\section{Publisher's Note}

Springer Nature remains neutral with regard to jurisdictional claims in published maps and institutional affiliations.

Ready to submit your research? Choose BMC and benefit from:

- fast, convenient online submission

- thorough peer review by experienced researchers in your field

- rapid publication on acceptance

- support for research data, including large and complex data types

- gold Open Access which fosters wider collaboration and increased citations

- maximum visibility for your research: over $100 \mathrm{M}$ website views per year

At BMC, research is always in progress.

Learn more biomedcentral.com/submissions 